\title{
A APLICAÇÃO DO PRECEDENTE JUDICIAL COMO EXPRESSÃO DO PRINCÍPIO DA BOA-FÉ: UMA VISÃO SOBRE CRÉDITOS DE ICMS DECORRENTES DE DOCUMENTOS INIDÔNEOS.
}

\author{
Marcelo da Silva dos Santos* \\ Eurico Moreira da Silva Junior ${ }^{* *}$
}

Resumo: O presente estudo cuida do precedente judicial e sua repercussão no direito brasileiro. A partir da análise conceitual e das principais características do instituto, procurase compreender a sua aplicação em um caso concreto. O objeto deste trabalho recai sobre as decisões judiciais do Superior Tribunal de Justiça que deram origem à Súmula 509, e quais os seus efeitos de vinculação. A Súmula 509 trata da observância do princípio da boa-fé para manutenção de créditos de ICMS decorrentes de aquisição de mercadorias/prestação de serviço de contribuintes cujos documentos tenham sido considerados inidôneos

Palavras-chave: precedente; princípio da boa-fé; créditos de ICMS; documentos inidôneos; Súmula 509

\section{THE APPLICATION OF THE JUDICIAL PRECEDENT AS AN EXPRESSION OF THE PRINCIPLE OF GOOD FAITH: A VIEW ON ICMS CREDITS ARISING FROM UNFAITHFUL DOCUMENTS}

\begin{abstract}
The present study takes care of the judicial precedent and its repercussion in Brazilian law. From the conceptual analysis and the main characteristics of the institute, it is tried to understand its application in a concrete case. The purpose of this paper is the judicial decisions of the Superior Court of Justice that gave rise to the "Súmula 509", and their binding effects. The "Súmula 509" addresses the observance of the principle of good faith for the maintenance of ICMS credits arising from the acquisition of goods/services rendered by taxpayers whose documents have been considered unfaithful
\end{abstract}

Keywords: precedente; principle of good Faith; ICMS credits; unfaithful documents; "Súmula 509"

\section{INTRODUÇÃO}

\footnotetext{
* Mestrando em Direito pelo Programa de Pós-Graduação em Direito da Universidade Federal do Rio de Janeiro. Bacharel em Direito da Universidade do Vale do Paraíba. Pesquisador do Laboratório de Estudos Teóricos e Analíticos sobre o Comportamento das Instituições (LETACI). Curriculum Lattes: http://lattes.cnpq.br/2452425227945362. E-mail: marcelodosnt@ gmail.com.

** Mestrando em Direito pelo Programa de Pós-Graduação em Direito da Universidade Federal do Rio de Janeiro. Bacharel em Direito da Faculdade Nacional de Direito da Universidade Federal do Rio de Janeiro. Pesquisador do Laboratório de Estudos Teóricos e Analíticos sobre o Comportamento das Instituições (LETACI). Curriculum Lattes: http://lattes.cnpq.br/8290753123273178. E-mail: emoreira@ufrj.com.
}

Revista de Direito Tributário e Financeiro | e-ISSN: 2526-0138 | Porto Alegre | v. 4 | n. 2 | p. 23 - 42 | Jul/Dez. 2018 
O estudo dos precedentes decorre, em sua origem, da Escola da Commom Law, tendo sido desenvolvido nos países de tradição anglo-saxônica, em especial na Inglaterra e nos Estados Unidos da América. No common law, as decisões judiciais proferidas em casos do passado formam um modelo coerente para a obtenção de regras e padrões que permitem a sua aplicação na solução de disputas atuais.

O precedente no ordenamento jurídico brasileiro vem, há algum tempo, sendo objeto de discussões entre os juristas pátrios. Contudo, nossa tradição jurídica romano-germânica ou de Direito Continental Europeu, baseada na Escola da Civil Law, sempre privilegiou a lei, ato emanado pelo Poder Legislativo, como fonte primária do Direito, razão pela qual se defende cautela em sua aplicação no Brasil. Neste sentido, os precedentes judiciais eram concebidos no Brasil como uma orientação, sem caráter obrigatório, mas persuasivo, para as decisões proferidas por tribunais inferiores e juízes singulares.

A importância dos precedentes no cenário nacional passou a ganhar corpo a partir da Constituição da República Federativa do Brasil de 1988, com a Emenda Constitucional no $3 / 93$ - que concedeu força vinculante às decisões de mérito do Supremo Tribunal Federal (STF) nas ações declaratórias de constitucionalidade de lei ou ato normativo federal - e posteriormente, com a Emenda Constitucional no 45/04 - que estendeu este efeito às decisões de emanadas pelo STF nas ações diretas de inconstitucionalidade ${ }^{1}$ - intensificando as controvérsias sobre a edição de súmulas vinculantes e seus efeitos.

Desde então, inúmeros debates acadêmicos e jurisprudenciais impulsionaram a adoção dos precedentes no ordenamento jurídico brasileiro, sedimentando-se com a entrada em vigor do Novo Código de Processo Civil ${ }^{2}$. Sob essa perspectiva, a palavra "lei" inserida do artigo $5^{\circ}$, inciso II, da Constituição Federal de 1988 passa ser compreendida como Direito. ${ }^{3}$

Este estudo propõe, a partir de uma breve análise conceitual, verificar, de forma dedutiva, como os precedentes podem ser compreendidos e aplicados no Brasil. Para tanto, pretende-se examinar como decisões do Superior Tribunal de Justiça (STJ) deram origem à Súmula 509 e quais os seus efeitos de vinculação. A Súmula 509 do STJ trata da observância

\footnotetext{
${ }^{1}$ Art. 102, § 2 ${ }^{\circ}$, da Constituição de 1988: "As decisões definitivas de mérito, proferidas pelo Supremo Tribunal Federal, nas ações diretas de inconstitucionalidade e nas ações declaratórias de constitucionalidade produzirão eficácia contra todos e efeito vinculante, relativamente aos demais órgãos do Poder Judiciário e à administração pública direta e indireta, nas esferas federal, estadual e municipal".

${ }^{2}$ Vide Lei $n^{\circ}$ 13.105/2015, Código de Processo Civil, artigos 489, § 1º, VI, c/c 926 e 927.

${ }^{3}$ Artigo $5^{\circ}$, inciso II, da Constituição de 1988: "ninguém será obrigado a fazer ou deixar de fazer alguma coisa senão em virtude de lei”.
}

Revista de Direito Tributário e Financeiro | e-ISSN: 2526-0138 | Porto Alegre | v. 4 | n. 2 | p. 23 - 42 | Jul/Dez. 2018 
do princípio da boa-fé ${ }^{4}$ para manutenção de créditos do imposto sobre operações relativas à circulação de mercadorias e sobre prestações de serviços de transporte interestadual, intermunicipal e de comunicação (ICMS), ${ }^{5}$ de competência dos estados-membros e Distrito Federal, que sejam decorrentes de aquisição de mercadorias/prestação de serviço de contribuintes, cujos documentos fiscais tenham sido declarados inidôneos pelos fiscos estaduais. Observa-se que, muito embora tenha havido decisão do STJ com repercussão geral e esta esteja materializada em uma Súmula, ainda assim pairam relevantes dúvidas e incertezas sobre o tema da formação do precedente no Brasil, motivo pelo qual se tornou necessário adentrar nessa discussão.

Por meio da análise conceitual, objetiva-se investigar como se dá a construção de um precedente e das terminologias que envolvem o seu estudo. Serão abordados os conceitos de ratio decidendi e obiter dictum, fatos materiais e imateriais e distinguish à luz dos ensinamentos de Arthur Lehman Goodhart. Em seguida, pretende-se verificar a posição do precedente a partir do ponto de vista de fonte de direito e compreender qual o poder de vinculação que ele pode gerar no ordenamento jurídico: precedentes verticais e horizontais, stare decisis e overruling, conforme lições de Frederick Schauer e Neil MacCormick.

\section{DETERMINANDO UM PRECEDENTE}

O sistema da Common Law concebido por alguns países, como a Inglaterra e os Estados Unidos da América, é um direito essencialmente jurisprudencial, em que pese o recente papel desempenhado pela legislação, com a importância cada vez maior da lei. O direito na common law se desenvolveu a partir da utilização da técnica de precedentes oferecidos pelas decisões judiciais. A obrigação de respeitar os precedentes está ligada com a capacidade de estabelecer distinções, onde o juiz, utilizando um conjunto de "precedentes", busca a solução para o novo caso a ele submetido, promovendo a evolução do direito (DAVID, 2006, p. 11-14).

\footnotetext{
${ }^{4}$ Sobre o princípio da boa-fé subjetiva: “[...] segundo Méndez (1997, p.53): ‘A boa-fé, que de conceito técnicojurídico evoluía, no Direito romano, para um lugar-comum retórico, não escaparia a este movimento. Dentro do Direito canônico, ganhou uma dimensão axiológica, a entender dentro do espírito do pensamento cristão.'” (apud REIS, 2008, p. 67). Sobre o princípio da boa-fé objetiva: "A boa-fé germânica partiu da ideia de crença, confiança, honra e lealdade, alargando o sentido romano de boa-fé, construindo assim uma teoria própria; a boafé objetiva, ligada ao racionalismo." (REIS, 2008, p. 68).

${ }^{5}$ Conforme o princípio da não-cumulatividade estabelecido pelo artigo 155 , § $2^{\circ}$, inciso I, da CRFB/88.
} 
Para compreensão inicial dos precedentes, inicialmente busca-se o conceito de precedente nos ensinamentos de John Salmond (1924), conforme citado por Goodhart (1930, p. 161): ${ }^{6}$

A precedent, therefore, is a judicial decision which contains in itself a principle. The underlying principle which thus forms its authoritative element is often termed the ratio "decidendi". The concrete decision is binding between the parties to it, but it is the abstract "ratio decidendi" which alone has the force of law as regards the world at large.

Em sequência, as regras de John Chipman Gray (1921) são mencionadas por Goodhart (1930, p. 161) para dar continudade à sua análise ao apontar os critérios necessários para que uma decisão judicial se torne um precedente: ${ }^{7}$

It must be observed that at the Common Law not every opinion expressed by a judge forms a Judicial Precedent. In order that an opinion may have the weight of a precedent, two things must concur: it must be, in the first place, an opinion given by a judge, and, in the second place, it must be an opinion the formation of which is necessary for the decision of a particular case; in other words, it must not be "obiter dictum".

Assim, Goodhart chama a atenção para o fato de que os dois autores por ele mencionado concordam quanto à importância de se determinar a ratio decidendi, esclarecendo que ambos param ao chegar a este ponto. Contudo, assevera a dificuldade de se compreender esse termo, uma vez que, as decisões do judiciário não estabelecem como ocorre a ligação que irá determinar o precedente em função da decisão. Faz-se necessário, então, entender a distinção (distinguish) entre o caso concreto e a ratio decidendi em abstrato. ${ }^{8}$

\footnotetext{
${ }^{6}$ Em tradução livre: "Um precedente, portanto, é uma decisão judicial que contém em si um princípio. O princípio subjacente que, deste modo, forma seu elemento impositivo é muitas vezes chamado de razão 'decidendi'. A decisão concreta é vinculativa entre as partes, mas é a 'ratio decidendi' abstrata, que sozinha tem força de lei em relação ao mundo em geral".

${ }^{7}$ Em tradução livre: "Deve-se observar que na Common Law nem todas as opiniões expressas por um juiz constituem um Precedente Judicial. Para que uma opinião possa ter o peso de um precedente, duas coisas devem coincidir: deve ser, em primeiro lugar, uma opinião dada por um juiz e, em segundo lugar, deve ser uma opinião cuja formação é necessária para a decisão de um caso específico; em outras palavras, não deve ser 'obiter dictum"."

${ }^{8}$ Aponta-se aqui a primeira cautela a ser adotada na incorporação de terminologias estrangeiras ao ordenamento nacional. O próprio autor ressalta a dificuldade de se compreender o que seria a ratio decidendi, deixando claro
}

Revista de Direito Tributário e Financeiro | e-ISSN: 2526-0138 | Porto Alegre | v. 4 | n. 2 | p. 23 - 42 | Jul/Dez. 2018 
Ao destacar o cuidado que se deve ter na busca da ratio decidendi das decisões que serviram de base para o precedente, evidencia-se que as razões que levaram à decisão nem sempre estão explícitas, Goodhart (1930, p. 164) esclarece que a primeira regra para descobrir a 'ratio decidendi' de um caso é que não deve ser procurada nas razões pelas quais o juiz baseou sua decisão. A partir da consideração de que o precedente não é encontrado na decisão judicial, mas na sua fundamentação, surge a necessidade de diferenciar a ratio decidendi, que realmente vincula os julgadores futuros, da obter dictum, comentários expressos por um juiz de forma incidental na sua decisão.

Isso decorre do fato de que os tribunais declaram suas razões para se chegar a uma conclusão. Contudo, frequentemente resumem o resultado em uma declaração geral da lei sobre o ponto em questão, de modo que, nem sempre, as razões das decisões estão explicitas.

Encontra-se um grande número de casos em que não há nenhuma opinião e, portanto, o princípio $^{9}$ que motivou a decisão deveria ser procurado em outro lugar. Neste sentido, Goodhart (1930, p. 165) afirma que um caso também pode ser um precedente, envolvendo um importante princípio de direito, embora o tribunal possa tê-lo julgado sem emitir uma opinião.

A partir dessa propositura, ele acredita que os fatos avaliados em uma decisão podem ser vistos de forma diferente por duas pessoas distintas. Sendo assim, propõe a análise dos julgados com base na classificação dos fatos como materiais e imateriais.

Os juízes devem considerar como material o fato que decorre de um conjunto de fatos selecionados que, na visão de um leigo podem ser significantes, contudo, para os operadores do direito se tornam insignificantes. Conclui que o julgamento dos juízes é baseado nesses fatos selecionados que serviram para o seu convencimento. É por meio dessa escolha de fatos materialmente relevantes que os juízes farão o Direito.

A compreensão de que os juízes fazem o Direito a partir de fatos materialmente relevantes, sugere um caminho para o entendimento do que seria a ratio decidendi. Entretanto, como identificar o fato materialmente relevante? Haveria regra que pudesse auxiliar nesse processo?

que esta é uma expressão das mais enganosas no direito inglês, tendo em vista que o motivo dado pelo juiz para a sua decisão nunca representa a parte vinculante do precedente (GOODHART, 1930, p. 162).

9 Pela compreensão do texto, entende-se que princípios seriam os argumentos fundamentais, o núcleo do pensamento que fundamentou a decisão, o elemento "material" não necessariamente explícito, como será visto adiante. Não devem ser confundidos com os "princípios” da era pós-positivista.

Revista de Direito Tributário e Financeiro | e-ISSN: 2526-0138 | Porto Alegre | v. 4 | n. 2 | p. 23 - 42 | Jul/Dez. 2018 
Invariavelmente seria uma tarefa difícil estabelecer uma fórmula que levasse a um resultado desejável. Contudo, Goodhart (1930) sugere alguns caminhos que devem ser trilhados pelos operadores do direito ao se defrontarem com os seus primeiros casos. ${ }^{10}$ Apesar de ser raro encontrar qualquer conflito real entre os fatos constantes na decisão e aqueles levantados nas argumentações, são de ocorrência frequente decisões onde os fatos relatados no parecer não incluem alguns dos fatos registrados nas argumentações.

Para essa circunstância, duas são as explicações possíveis: $i$ ) o fato foi considerado pelo Tribunal, mas foi encontrado para ser imaterial; ou ii) o fato no registro da argumentação não foi considerado pelo tribunal porque o advogado não chamou a atenção para ele ou foi por algum outro motivo negligenciado.

Percebe-se, então, a fundamental importância de se estabelecer de forma precisa quais são os fatos materiais relevantes nos julgados (ratio decidendi), pois será isso que os difernciará da dicta (obiter dictum).

Quando estamos diante de uma decisão onde não é possível identificar o fato material que deu suporte à sentença, então não se pode estabelecer qual foi o princípio fundamental, assim, estaríamos diante do que se denomina "obiter dictum". A dificuldade de se saber se estamos diante da dicta ou não, reside no fato de saber se a sentença se baseou em fato hipotético ou real e, para deixar clara a diferença Goodhart (1930, p. 179 e 180) conclui:

When a judge says, 'In this case, as the facts are so and so, I reach conclusion $X$,' this is not a dictum, even though the judge has been incorrect in his statement of the facts. But if the judge says, 'If the facts in this case were so and so then I would reach conclusion $X$,' this is a 'dictum', even though the facts are as given. ${ }^{11}$

Estabelecida a distinção entre ratio decidendi e dicta, percebe-se que o conceito de distinguish surge naturalmente, pois será pela análise do elemento materialmente relevante da decisão que se estabelecerão as semelhanças e distinções dos casos para sua adequação ao precedente.

\footnotetext{
${ }^{10}$ Para Goodhart (1930, p. 169), se não existe opinião, ou se a opinião não tem uma declaração dos fatos, então supõe-se que todos os fatos dados no relatório são materiais, salvo os que, aparentemente, não são. Assim, os fatos de pessoa, tempo, lugar, tipo e quantidade são supostamente imateriais, exceto os declarados materiais.

${ }^{11}$ Em tradução livre: "Quando um juiz diz: 'Neste caso, como os fatos são assim e assim, eu chego à conclusão $X^{\prime}$, isto não é um dictum, mesmo que o juiz esteja incorreto em sua declaração dos fatos. Mas se o juiz disser: 'Se os fatos neste caso fossem assim e assim, então eu chegaria à conclusão X', este é um 'dictum', mesmo que os fatos sejam os mesmos."
}

Revista de Direito Tributário e Financeiro | e-ISSN: 2526-0138 | Porto Alegre | v. 4 | n. 2 | p. 23 - 42 | Jul/Dez. 2018 
Compreendidos os conceitos de ratio decidendi, dicta e distinguish, o próximo passo é identificar se o caso é ou não um precedente vinculativo que deverá ser seguido. Na visão de Goodhart (1930, p. 180) isso envolve duas análises: $i$ ) Primeiro deve-se identificar os fatos materialmente relevantes no primeiro caso e depois verificar se são os mesmos no segundo caso. Se as circunstâncias de fato materialmente são idênticas, então estamos diante de um precedente de vinculação. ii) Segundo, se o primeiro caso carece de qualquer fato material ou contém características não encontradas no segundo, então não há o que se falar em precedente vinculante.

Até aqui, conclui-se que o autor deixou bem nítido a importância de se determinar a ratio decidendi, estabelecendo sua diferenciação com a obter dictum (dicta), evidenciando que a distinguish pode ser utilizada tanto para estabelecer a distição entre ratio e dictum, bem como para caracterizar/descaracterizar a vinculação entre uma decisão e outra.

As lições de Goodhart (1930) permitiram uma compreensão acerca do procedente judicial, com referência no estudo do Direito, durante o período compreendido entre o secúlo XIX e o início do século XX. Contudo, para uma adicional compreensão da força vinculante dos precedentes nos dias atuais, torna-se necessário buscar auxílio no jurista Frederick Schauer, que possui relevante estudo sobre precedentes.

\section{PRECEDENTE COMO FONTE DO DIREITO E SUA FORÇA VINCULANTE}

A partir da segunda metade do século XX, as teorias positivistas que influenciaram os sistemas codificados no início daquele século perderam força e as leis deixaram de ser fonte exclusiva do Direito, dando espaço às interpretações com base no Direito Constitucional, notadamente nos Direitos Fundamentais à luz dos valores, da moral ${ }^{12}$ e dos princípios. $^{13}$

Esse reflexo se fez sentir no ordenamento jurídico brasileiro com a CRFB/88, que incorporou, de forma expressa, os Direitos Fundamentais e Sociais e o controle de constitucionalidade atribuído ao Supremo Tribunal Federal.

\footnotetext{
${ }^{12}$ Conforme a chamada Virada Kantiana, que representa a reaproximação do Direito com a ética e a moral, a partir do trabalho de John Rawls (2008).

${ }^{13}$ Ronald Dworkin (2014) constrói sua teoria dos princípios com a finalidade de criticar a discricionariedade de interpretação utilizada no positivismo.
} 
Embora essa tendência pós-positivista de ver o Direito com fundamentos em valor e moral - o que seria um caminho, tendo em vista que a Súmula 509 do STJ trata do princípio da boa-fé - optou-se, nesse estudo, pela teoria de Schauer que vê o precedente como direito positivo presuntivo. Defende o autor que o Direito é regra carregada de generalidade, devendo ser aplicado de forma genérica, ainda que o operador do direito se depare com um resultado não tão correto. Nesse sentido, o precedente é a maneira pela qual regras gerais irão se enraizar no Commom Law.

Ao invocar a generalidade, Schauer $(2009$, p. 14) alerta que as regras podem ser interpretadas de diversas maneiras, por isso defende que elas devem ser analisadas sob três aspectos: raciocínio jurídico, argumentos jurídicos e tomada de decisão jurídica, reforçando sua fidelidade à Escola Legalista.

Neste ponto, pertinentes são os argumentos de Goodhart (1930, p. 169) quando diz que o juiz fundamenta suas conclusões sobre um conjunto de fatos selecionados por ele como materiais dentre uma gama maior de fatos, alguns dos quais podem parecer significativos para um leigo, mas que, para um advogado, são irrelevantes. Segundo esta passagem, os juízes, na maioria das vezes, têm condições de julgar melhor que o cidadão comum, pois conhece a lei.

Frederick Schauer $(2009$, p. 15) sustenta que toda regra tem um rationale ou background justificacion, e, portanto, deve ser procurado, na regra, a sua justificativa de fundo. Essa assertiva parte da análise de um exemplo que o autor traz para ilustrar a construção do seu raciocínio. Ele considera que uma placa de limite de velocidade pode ser desrespeitada com argumentos palusíveis, tais como: em uma manhã ensolarada, com a pista vazia, um condutor pode concluir que, considerando sua habilidade de direção, andar a 55 $\mathrm{km} / \mathrm{h}$ seria uma baixa velocidade para aquelas condições, e decidir que poderia dirigir a 70 $\mathrm{km} / \mathrm{h}$, e ainda assim estar amparado em uma condição segura. Com esse exemplo simples, o autor procura evidenciar que as regras servem para reduzir um acordo entre as partes a uma forma escrita, para deixar claros os motivos que, às vezes, não são considerados nas análises pessoais. Senão, veja-se: outro motorista, na mesma pista vazia, porém com menor habilidade de direção, poderia achar que, também, poderia exceder os limites de velocidade por ter cido ultrapassado e, por consequência, vir a colidir. 
Nota-se que o exemplo traz à tona a circunstância de que, por questões técnicas e de preservação da vida humana, o limite deve ser $55 \mathrm{~km} / \mathrm{h}$. Essa seria a medida a ser considerada para que um ser humano médio (caráter de generalidade) pudesse ter segurança (justificativa).

Esse simples exemplo conduz à conclusão de que as numerosas opções postas à nossa disposição pela linguagem fazem com que a generalização seja um processo seletivo, no qual as várias propriedades do particular sejam, simultaneamente, incluídas e excluídas. Por conseguinte, ao derivar de um caso particular (precedente), a generalizão evita que consequências inoportunas possam se propagar de forma geral.

Um problema levantado por Schauer em relação a essa generalização é que a universalização pode ser imprecisa. Para lidar com essa questão, ele apresenta dois modelos: conversão e enraizamento (MAUÉS, 2012).

Pela conversão, os atores envolvidos no cenário realimentam a generalização com fundamentos que demonstram a impropriedade da regra, fazendo que ela seja revista. Contudo, há situações tão profundamente enraizadas que, a ação dos atores pouco afetará o cenário, tornando difícil qualquer mudança de paradigma.

Antonio Maués (2012, p. 4-6) conclui que, na visão de Schauer, será essa dinâmica que construirá o precedente e sua força de vinculação. Com base na carga histórica dos julgados e no seu enraizamento os juízes aplicarão os precedentes como regras.

Considerando que o estudo dos precedentes como regra de vinculação é um pouco mais complexo, Schauer (2009, p. 36) tratou de estabelecer uma classificação quanto à força de vinculação da seguinte forma: precedentes verticais e horizontais.

Precedentes verticais seriam aqueles em que cortes e juízes de grau inferior ao que proferiu a decisão em jurisdição superior estão obrigados a seguir o mandamento da corte superior por uma questão básica de hierarquia. Precedentes horizontais seriam aqueles decorrentes de decisões tomadas no passado por uma mesma corte, nesse caso a decisão seria vinculante não porque foi emanada de uma corte superior, mas pelo fato de ter sido proferida anteriormente. A obrigação de um tribunal de seguir suas próprias decisões anteriores é tipicamente conhecida como "stare decisis", expressão latina para "manter a coisa decidida", constituindo uma forma distinta de restrição por precedente (SCHAUER, 2009, p. 37).

Entre Goodhart (1930) e Schauer (2009), observa-se um lapso temporal de mais de 70 anos, entretanto, nota-se que a tônica principal que gira em torno dos precedentes continua 
sendo como se determinar a ratio decidendi, Schauer, assim como Godhart, buscou perseguir a background justificacion.

A metodologia utilizada por Schauer (2009) para demonstrar a força de vinculação dos precedentes, classificando-os como verticais e horizontais, contribuiu, sobremaneira, para compreensão do conceito de stare decisis, revelando a importância da coisa julgada e da segurança jurídica, como será desenvolvido a seguir.

\section{OVERRULING E SEGURANÇA JURÍDICA}

Estabelecido o conceito de stare decisis, pode-se avançar paro o entendimento daquilo que seria o overrruling. Contudo, faz-se necessário entender o que seriam os hard cases, na visão de Schauer, e com eles influenciam a stare decisis.

A partir do simples exemplo da placa de limitação de velocidade, evidenciou-se o caráter de generalidade do precedente, como, também, esclareceu-se a necessidade de se buscar a função essencial da regra (background justificacion). Em casos simples como esse, as argumentações são facilmente identificadas e ponderadas. Porém, exintem situações nas quais se torna difícil (hard cases) a tomada de decisão, devido ao alto grau de complexidade das argumentações envolvidas no litígio. ${ }^{14}$

As contingências (selection effect) geradas pelos hard cases favorecem o aprofundamento das argumentações dos juízes da corte, o que dá robustez às decisões, justificando, desta feita, a força vinculante da stare decisis. O efeito disso é o respeito à coisa julgada e a segurança jurídica, tão necessários no Estado de Direito.

Sobre esse tema, chamou-se ao diálogo Neil MacCormick (2008, p. 18), que defende o princípio da segurança jurídica como elemento fundamental para o Estado de Direito. Contudo, ele sugere que o Direito não tem em si um valor moral, por isso, as regras legalmente estabelecidas, podem, às vezes, estar longe do ideal moral esperado. Com isso não quer dizer que o Direito seja sempre certo ao passo que a moralidade é incerta, pois o revés às vezes acontece.

\footnotetext{
${ }^{14}$ Como as aplicações diretas ou fáceis de regras jurídicas raramente são judicializadas, os casos que chegam a um tribunal são predominantemente e desproporcionalmente aqueles que, de alguma forma, são difíceis. Os casos difíceis litigados, portanto, representam uma amostra parcial de todos os eventos legais, um fenômeno normalmente chamado de efeito de seleção (SCHAUER, 2009, p. 13).
}

Revista de Direito Tributário e Financeiro | e-ISSN: 2526-0138 | Porto Alegre | v. 4 | n. 2 | p. 23 - 42 | Jul/Dez. 2018 
Segundo o autor o "lugar comum" esta aí pra ser questionado, tudo é passível de argumentação, não há argumentação procrastinatória, aquela que desvirtuou a retórica, mas uma argumentação lógico-jurídica que possa revelar a riqueza de uma "nova retórica", fundada na "razão prática" (MACCORMICK, 2008, p. 28).

Sua leitura crítica da "razão prática" irá levá-lo a fazer uma ponderação dos procedimentos necessários para o seu uso. Assim, procurou analisar a questão da universalidade das razões. É claro que existem lugares comuns em que uma argumentação, por mais sustentável que seja, não pode atingir (situações enraizadas na visão de Schauer), porém, se surgem novos fatos que possam colocar aquilo que, universalmente, estava sedimentado em ponto de questionamento, o Direito deve estar aberto a considerar.

Ele valoriza o Estado de Direito, onde leis e precedentes têm o seu valor como garantidores da segurança e da estabilidade da vida social, contudo, pondera que há espaço para a argumentação jurídica a partir dessas disposições normativas, diante de determinado fato, ou conjunto de fatos operativos. Nesse sentido, faz as seguintes considerações:

"Uma regra jurídica é uma disposição normativa estabelecida em ou interpretada a partir de uma fonte jurídica reconhecida que tem a característica de relacionar uma determinada consequência normativa a um determinado conjunto de fatos operativos." (MACCORMICK, p. $33)$.

MacCormick (1941) conclui que a identificação do elemento vinculante ou especificamente persuasivo por meio dos fatos operativos, em um precedente, é uma questão importante, pois será esse elemento que dará força à ratio decidendi, tornando-a mais ou menos persuasiva em relação às decisões posteriores.

Ao considerar o argumento de que as decisões são tomadas na moldura de algum tipo de lei estabelecida ou institucionalizada, o autor destaca a importância da sua teoria da argumentação, afirmando que "[...] mesmo onde precedentes são tratados como persuasivos e não como absolutamente vinculantes, é necessário existir uma forte presunção contra desvios ou mudanças do que já foi decidido [...]” (MACCORMICK, 1941, p. 199), para que o precedente possa ser superado (overruling).

Dessa forma ressalta a importância de se fundamentar adequadamente as razões para superação de um precedente, delimitando um campo para a discussão - Razão Prática - da 
argumentação jurídica, o que em sua visão seria a justificação jurídica, que, apesar de considerar aspectos morais, não se confunde com a argumentação moral.

Com essas considerações sobre a teoria dos precedentes, procurou-se dar o subsídio necessário ao estudo da Súmula $\mathrm{n}^{\circ} 509$, do STJ, e estabelecer um ponto de partida para reflexão dos seus efeitos.

\section{SÚMULA STJ No 509 À LUZ DA TEORIA DOS PRECEDENTES}

No estudo dos precedentes procurou-se delimitar alguns conceitos, de igual forma será feito no estudo da Súmula $n^{\circ} 509$, considerando a necessidade de compreensão do seu background justificacion.

O enunciado da Súmula n. 509 do STJ se faz da seguinte forma: “É lícito ao comerciante de boa-fé aproveitar os créditos de ICMS decorrentes de nota fiscal posteriormente declarada inidônea, quando demonstrada a veracidade da compra e venda" (BRASIL, 2014).

Primeiramente vamos tratar do que sejam créditos de ICMS. O ICMS é um imposto de competência estadual, previsto no artigo 155 e seguintes da $\mathrm{CF} / 88$, será não cumulativo devendo ser compensado o que for devido em cada operação relativa à circulação de mercadorias ou prestação de serviços com o montante cobrado nas anteriores ${ }^{15}$. Por conseguinte, é garantido ao sujeito passivo o direito de creditar-se do imposto anteriormente cobrado em operações de que tenham resultado a entrada de mercadoria, real ou simbólica, no estabelecimento do comerciante. ${ }^{16}$

Em segundo lugar passamos à compreensão do que é nota fiscal declarada inidônea. O contribuinte do ICMS, para o regular exercício de sua atividade deve estar devidamente

15 Cf. Princípio da não cumulatividade, artigo 115, § 2º inciso I, da Constituição Federal de 1988.

16 Os artigos 19 e 20 da Lei Complementar n. 87/1996 dispõe que: "art. 19. O imposto é não-cumulativo, compensando-se o que for devido em cada operação relativa à circulação de mercadorias ou prestação de serviços de transporte interestadual e intermunicipal e de comunicação com o montante cobrado nas anteriores pelo mesmo ou por outro Estado"; e "art. 20. Para a compensação a que se refere o artigo anterior, é assegurado ao sujeito passivo o direito de creditar-se do imposto anteriormente cobrado em operações de que tenha resultado a entrada de mercadoria, real ou simbólica, no estabelecimento, inclusive a destinada ao seu uso ou consumo ou ao ativo permanente, ou o recebimento de serviços de transporte interestadual e intermunicipal ou de comunicação. $\S 1^{\circ}$ Não dão direito a crédito as entradas de mercadorias ou utilização de serviços resultantes de operações ou prestações isentas ou não tributadas, ou que se refiram a mercadorias ou serviços alheios à atividade do estabelecimento. $\$ 2^{\circ}$ Salvo prova em contrário, presumem-se alheios à atividade do estabelecimento os veículos de transporte pessoal. $\S 3^{\circ}$ É vedado o crédito relativo a mercadoria entrada no estabelecimento ou a prestação de serviços a ele feita".

Revista de Direito Tributário e Financeiro | e-ISSN: 2526-0138 | Porto Alegre | v. 4 | n. 2 | p. 23 - 42 | Jul/Dez. 2018 
cadastrado na Secretaria de Fazenda de Estado e cumprir regularmente as obrigações principais e acessórias ${ }^{17}$ a que estiver submetido. Caso isso não ocorra, os documentos por ele emitidos poderão ser declarados inidôneos.

As Secretarias de Fazenda dos Estados, em respeito ao princípio da federação ${ }^{18}$, têm total autonomia para regular o processo pelo qual os documentos dos contribuintes do ICMS serão declarados inidôneos.

Por exemplo, no Estado de São Paulo o processo é regulado pela Portaria CAT No 95/2006 ${ }^{19}$, que garante o contraditório e a ampla defesa, antes de declarar a inscrição estadual do contribuinte como inapta. Como decorrência da inaptidão da inscrição estadual, eventuais documentos emitidos por uma empresa considerada inapta, em data posterior à declaração de sua inaptidão, são considerados inidôneos.

A declaração de inidoneidade fiscal é um instrumento que os Fiscos Estaduais utilizam para impedir que contribuintes do ICMS em situação irregular emitam notas fiscais consideradas inidôneas. Como consequência, o comerciante adquirente de mercadorias ou serviços sujeitos à incidência do ICMS encontrava-se impedido de efetuar o aproveitamento do respectivo crédito de ICMS devido à declaração de inidoneidade da nota fiscal emitida pela empresa vendedora.

Os questionamentos sobre a legitimidade do crédito do ICMS decorrente de documento inidôneo surgem quando os processos de inidoneidade geram efeitos ex tunc, ou seja, os documentos são considerados inidôneos em período anterior ao da instauração do processo de inaptidão da inscrição estadual. E como isso seria possível?

Mesmo com advento de inúmeros controles fiscais eletrônicos, existem empresas que adotam estruturas sofisticadas de sonegação fiscal ou, simplesmente, se organizam para a venda de notas fiscais frias ou transferência de créditos espúrios de ICMS, de forma que o fisco só toma conhecimento dos fatos em data posterior. Essa prática de evasão/elisão abusiva $^{20}$ compromete o princípio da não cumulatividade, pois, o ICMS devido na etapa anterior não chega aos cofres do erário.

\footnotetext{
${ }_{17}^{17}$ Sobre o tema obrigação principal e acessória ver o artigo 113 da Lei no 5.172/66, Código Tributário Nacional.

${ }_{18} \mathrm{Cf}$. artigo $1^{\circ}$, c/c 18 e 155, da Constituição Federal de 1988.

${ }^{19}$ Portaria CAT No 95, de 24/11/2006 do Coordenador da Administração Tributária da Secretaria de Fazenda do Estado de São Paulo, DOE-SP: 25.11.2006 - republicada no DOE-SP de 01.12.2006. Dispõe sobre a suspensão, cassação e nulidade da eficácia da inscrição no Cadastro de Contribuintes do ICMS e dá outras providências.

${ }^{20}$ Para diferenciar evasão e elisão fiscal ver Elcio Fonseca Reis (2008. p. 192-220).
} 
Há casos em que, de certa forma, acaba havendo conluio do adquirente, ou simplesmente, culpa in vigilando ou in eligendo ${ }^{21}$, o que gera as controvérsias em torno do precedente trazido pela Súmula $n^{\circ} 509$.

O precedente se funda no princípio da boa-fé, quando demonstrada a veracidade da operação de compra e da venda ocorrida. Percebe-se que, embora possa denotar certa inclinação para a boa-fé objetiva (veracidade da operação comercial), o precedente traz um elemento de generalidade, conforme ensinado por Schauer (2009), pois: Como aferir a veracidade da compra e da venda? Como identificar se não houve conluio entre as partes? Até onde houve culpa in vigilando ou in eligendo?

Afinal, onde conseguiremos buscar a razão prática, o fato operativo, nos dizeres de MacCormick, que adequará o caso concreto à ratio decidendi? Para esta análise, mencionamse, a seguir, os precedentes que embasaram a Súmula $n^{\circ} 509$.

No Recurso Especial (REsp) no 1.148.444/MG ${ }^{22}$, que foi julgado em 14/04/2010, com a relatoria do Ministro Luiz Fux, e submetido ao procedimento dos recursos repetitivos, a Primeira Seção do STJ entendeu que o comerciante de boa-fé que adquire mercadoria, cuja nota fiscal emitida pela vendedora foi declarada inidônea após a celebração do negócio jurídico, legitima o aproveitamento do crédito do ICMS pelo princípio da nãocumulatividade. Fundamentou a Corte que, uma vez demonstrada a veracidade da compra e venda efetuada, o ato declaratório da inidoneidade emitido somente produz efeitos a partir de sua publicação. Neste sentido, a responsabilidade do adquirente de boa-fé reside na exigência, no momento da celebração do negócio jurídico, da documentação pertinente à assunção da regularidade do alienante, cuja verificação de idoneidade compete ao Fisco, não incidindo, no caso, o artigo 136 do Código Tributário Nacional, que trata da responsabilidade por infrações da legislação tributária.

Posteriormente, a Primeira Turma do STJ adotou idêntico entendimento do Recurso Especial no 1.148.444/MG no julgamento do Agravo Regimental no Agravo de Instrumento

\footnotetext{
${ }^{21}$ Em matéria tributária, cabe ao adquirente da mercadoria/prestação de serviço a obrigação de verificar a regularidade do seu fornecedor, cf. artigo 22-A da Lei 6.374/89: "Sempre que um contribuinte, por si ou seus prepostos, ajustar a realização de operação ou prestação com outro contribuinte, fica obrigado a comprovar a sua regularidade perante o fisco, de acordo com o item 4 , do $\S 1^{\circ}$, do artigo 36 , e também a exigir o mesmo procedimento da outra parte, quer esta figure como remetente da mercadoria ou prestador do serviço, quer como destinatário ou tomador, respectivamente".

${ }^{22}$ Vide Recurso Especial nº 1.148.444/MG, DJe: 27/04/2010.
} 
(AgRg no $\mathrm{Ag}$ ) $\mathrm{n}^{\mathrm{o}}$ 1.239.942/SP ${ }^{23}$, em 01/09/2011, relatoria do Ministro Arnaldo Esteves Lima. Sucessivamente, o mesmo posicionamento foi acatado nos julgamentos realizados pela Segunda Turma no Agravo Regimental no Agravo em Recurso Especial (AgRg no AREsp) no 91.004/SP ${ }^{24}$, de 16/02/2012, relatoria de Ministro Humberto Martins; pela Segunda Turma no Agravo Regimental no Agravo em Recurso Especial (AgRg no AREsp) n ${ }^{\text {o }}$ 80.470/SP ${ }^{25}$, de 12/06/2012, relatoria do Ministro Herman Benjamin; pela Primeira Turma no Agravo Regimental nos Embargos de Declaração no Agravo em Recurso Especial (AgRg nos EDcl no AREsp) $n^{\circ} 102.473 / \mathrm{SP}^{26}$, de 26/06/2012, relatoria do Ministro Benedito Gonçalves; pela Primeira Turma nos Embargos de Declaração nos Embargos de Declaração no Recurso Especial (EDcl nos EDcl no REsp) no 1.215.222/SP ${ }^{27}$, de 14/08/2012, relatoria do Ministro Napoleão Nunes Maia Filho; e pela Segunda Turma no Agravo Regimental no Recurso Especial (AgRg no REsp) $n^{\circ} 1.228 .786 / \mathrm{SP}^{28}$, de 21/08/2012, relatoria do Ministro Castro Meira.

Em princípio, pelos julgados que precederam a edição da Súmula, percebe-se que o STJ solidificou entendimento de que a boa-fé seria a rationale (ratio decidendi), tratando como dicta as argumentações com base no princípio da não cumulatividade e o da não surpresa (que se conforma com a segurança jurídica), estabelecendo que os efeitos da inidoneidade só pudessem ser aplicados a partir da publicação da decisão.

Entretanto, ao avaliar a existência de decisões divergentes ${ }^{29}$ sobre a manutenção de créditos de ICMS, provenientes de documentos considerados inidôneos, em condições onde o adquirente de boa fé alegou em sua defesa a Súmula $\mathrm{n}^{\circ} 509$, verificou-se que o elemento material da ratio decidendi seria demonstrar a veracidade da compra e da venda. Portanto, a boa-fé, neste sentido, passa a ser dicta, na medida em que seu elemento de subjetividade não garante, em absoluto, o direito ao creditamento do imposto.

Com isso, conclui-se que, as decisões que não seguiram o precedente, não contiveram qualquer problema de vinculação vertical, tampouco horizontal, na adoção do

\footnotetext{
${ }^{23}$ Vide Agravo Regimental no Agravo de Instrumento no 1.239.942/SP, DJe: 09/09/2011.

${ }^{24}$ Vide Agravo Regimental no Agravo em Recurso Especial n ${ }^{\circ}$ 91.004/SP, DJe: 27/02/2012.

${ }^{25}$ Vide Agravo Regimental no Agravo em Recurso Especial no 80470/SP, DJe: 26/06/2012.

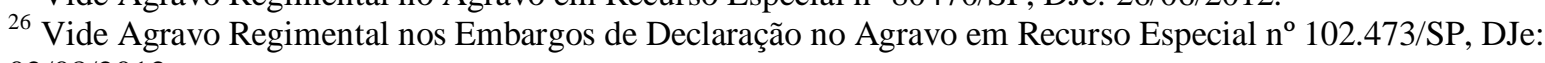
02/08/2012.

${ }^{27}$ Vide Agravo Regimental no Recurso Especial n ${ }^{\circ}$ 1.215.222/SP, DJe: 22/08/2012.

${ }^{28}$ Vide Agravo Regimental no Recurso Especial no 1.228.786/SP, DJe: 29/08/2012.

${ }^{29}$ Sobre decisões divergentes acessar Consultas de Jurisprudência da página de internet do Tribunal de Justiça de São Paulo. Disponível em: <http://esaj.tjsp.jus.br/cjpg/>. Acesso em: 31 jul. 2018.
} 
precedente, pois, o que de fato ocorreu foram os problemas alertados por Goodhart (1930): $i$ ) o fato foi considerado pelo Tribunal, mas foi encontrado para ser imaterial, ou $i$ ) o fato no registro da argumentação não foi considerado pelo tribunal porque o advogado não chamou a atenção para ele ou foi por algum outro motivo negligenciado.

Portanto, nos casos de créditos indevidos decorrentes de documentos considerados inidôneos pelo fisco, verifica-se que o olhar do juiz está mais atento aos elementos materiais do que aos imateriais, tornando imprescindível que a sustentação da defesa se preocupe em garantir todos os elementos de prova necessários para a caracterização da boa-fé.

\section{CONCLUSÃO}

Diante dos elementos trazidos nesse estudo, conclui-se que, embora possa haver divergêmcias para o uso dos precedentes no ordemanento jurídico brasileiro, é possível adotálos desde que se tomem as devidas cautelas.

Procurou-se compreender os elementos conceituais dos precedentes, mediante o estudo de teóricos que, ao longo de décadas, labutaram nesta seara.

Goodhart (1930) ensinou a importância da ratio decidendi e sinalizou um caminho que se mostrou eficaz na compreensão do termo. Demonstrou a necessidade de se distinguir os elementos materiais e imaterias que fundamentaram a decisão que deu origem ao precedente, e que nem sempre é tarefa fácil identificar os princípios adotados pelos julgadores, pois, eles, às vezes, não estão claros.

Ao discorrer sobre o caráter de generalidade das regras, Schauer (2009) ensinou que, pela conversão e pelo enraizamento, o precedente ganha força como fonte do Direito. Também, estabeleceu uma classificação em função da força vinculante dos precedentes (verticais e horizontais) e como essa classificação afeta o poder de vinculação. Esse estudo contribuiu para a percepção de como o conceito de stare decisis é importante para a manutenção do Estado de Direito, privilegiando-se a coisa julgada e a segurança jurídica.

Para MacCormick (1941), a segurança jurídica também é um fator crucial no Estado de Direito, contudo, o autor abre a possibilidade para o uso da teoria da argumentação, por meio da razão prática, como elemento útil a ser aplicado nos casos em que a generalidade não atende o Direito.

Revista de Direito Tributário e Financeiro | e-ISSN: 2526-0138 | Porto Alegre | v. 4 | n. 2 | p. 23 - 42 | Jul/Dez. 2018 
Por fim, a partir da aplicação dos conceitos teóricos aprendidos, a análise da Súmula $\mathrm{n}^{\mathrm{o}} 509$, possibilitou concluir que poderia haver uma tendência a considerar que o precedente enunciado pela Súmula não funciona, pois, a existência de decisões divergentes poderia demonstrar desrespeito ao princípio boa-fé. Entretanto, verificou-se que a má compreensão do elemento material que deu suporte à decisão paradigma tem distorcido o a interpretação do que seria a ratio decidendi.

Os argumentos de razão prática ensinados por MacCormick (1941), quando aplicáveis a analise das decisões paradigmas que deram origem ao precedente, permitem concluir que elas foram fundamentadas no exame criterioso dos "fatos operativos" que deram suporte às operações/prestações geradoras do crédito do imposto, tornando-os o núcleo central da decisão (background justificacion).

Assim, o estudo pretendeu demonstrar a necessidade de amadurecimento das discussões sobre precedente no ordenamento jurídico brasileiro, e que, para compreender os julgamentos de autuações fiscais que tratem do tema créditos indevidos de ICMS decorrentes de documentos inidôneos, faz-se necessário verificar, com profundidade, os elementos materias que foram utilizados para comprovação da boa-fé. 


\section{REFERÊNCIAS}

BRASIL. Constituição Federal de 1988. 53. ed. São Paulo: Saraiva, 2016.

. Lei n. 13.105, de 16 março 2015. Código de Processo Civil. Diário Oficial [da]

República Federativa do Brasil, Brasília, 17 mar. 2015. Disponível em:

<http://www.planalto.gov.br/ccivil_03/_Ato2015-2018/2015/Lei/L13105.htm>. Acesso em:

28 jul. 2018.

Lei n. 5.172, de 25 outubro 1966. Código Tributário Nacional. Dispõe sobre o

Sistema Tributário Nacional e institui normas gerais de direito tributário aplicáveis à União,

Estados e Municípios. Diário Oficial [da] República Federativa do Brasil, Brasília, 27 out. 1966, ratificado em 31 out. 1966. Disponível em:

<http://www.planalto.gov.br/ccivil_03/leis/L5172.htm>. Acesso em: 30 jul. 2018.

. Lei Complementar n. 87, de 13 de setembro de 1996. Dispõe sobre o imposto dos Estados e do Distrito Federal sobre operações relativas à circulação de mercadorias e sobre prestações de serviços de transporte interestadual e intermunicipal e de comunicação, e dá outras providências (LEI KANDIR). Diário Oficial [da] República Federativa do Brasil, Brasília, 16 set. 1996. Disponível em:

<http://www.planalto.gov.br/ccivil_03/leis/LCP/Lcp87.htm>. Acesso em: 30 jul. 2018.

Superior Tribunal de Justiça. Agravo Regimental no Agravo de Instrumento n. 1239942/SP, Relator: Ministro Arnaldo Esteves Lima, Primeira Turma, julgado em 01/09/2011. Diário da Justiça Eletrônico, Brasília, 09 set. 2011. Disponível em: $<$ https://ww2.stj.jus.br/processo/revista/inteiroteor/?num_registro=200901965760\&dt_publica cao=09/09/2011 >. Acesso em: 14 jun. 2018.

. Agravo Regimental no Agravo em Recurso Especial n. 80470/SP, Relator:

Ministro Herman Benjamin, Segunda Turma, julgado em 12/06/2012. Diário da Justiça Eletrônico, Brasília, 26 jun. 2012. Disponível em:

<https://ww2.stj.jus.br/processo/revista/inteiroteor/?num_registro=201101973525\&dt_publica cao=26/06/2012>. Acesso em: 14 jun. 2018.

. Agravo Regimental no Agravo em Recurso Especial n. 91004/SP, Relator:

Ministro Humberto Martins, Segunda Turma, julgado em 16/02/2012. Diário da Justiça Eletrônico, Brasília, 27 fev. 2012. Disponível em:

$<$ https://ww2.stj.jus.br/processo/revista/inteiroteor/?num_registro=201102107064\&dt_publica cao $=27 / 02 / 2012>$. Acesso em: 14 jun. 2018.

Agravo Regimental nos Embargos de Declaração no Agravo em Recurso

Especial n. 102473/SP, Relator: Ministro Benedito Gonçalves, Primeira Turma, julgado em 26/06/2012. Diário da Justiça Eletrônico, Brasília, 02 ago. 2012. Disponível em: $<$ https://ww2.stj.jus.br/processo/revista/inteiroteor/?num_registro=201102413537\&dt_publica cao $=02 / 08 / 2012>$. Acesso em: 14 jun. 2018.

Revista de Direito Tributário e Financeiro | e-ISSN: 2526-0138 | Porto Alegre | v. 4 | n. 2 | p. 23 - 42 | Jul/Dez. 2018 
Agravo Regimental no Recurso Especial n. 1228786/SP, Relator: Ministro Castro Meira, Segunda Turma, julgado em 21/08/2012. Diário da Justiça Eletrônico, Brasília, 29 ago. 2012. Disponível em:

<https://ww2.stj.jus.br/processo/revista/inteiroteor/?num_registro=200901611105\&dt_publica cao=29/08/2012>. Acesso em: 14 jun. 2018.

Embargos de Declaração nos Embargos de Declaração no Recurso Especial n. 1215222/SP, Relator: Ministro Napoleão Nunes Maia Filho, Primeira Turma, julgado em 14/08/2012. Diário da Justiça Eletrônico, Brasília, 22 ago. 2012. Disponível em: $<$ https://ww2.stj.jus.br/processo/revista/inteiroteor/?num_registro=201001790150\&dt_publica cao=22/08/2012>. Acesso em: 14 jun. 2018.

Recurso Especial n. 1148444/MG, Relator: Ministro Luiz Fux, Primeira Seção, julgado em 14/04/2010, Diário da Justiça Eletrônico, Brasília, 27 abr. 2010. Disponível em:

<https://ww2.stj.jus.br/processo/revista/inteiroteor/?num_registro=200900143826\&dt_publica cao=27/04/2010>. Acesso em: 14 jun. 2018.

. Súmula n. 509. Diário da Justiça Eletrônico, Brasília, 31 mar. 2014. Disponível em: <http://www.stj.jus.br/SCON/sumanot/toc.jsp>. Acesso em: 27 jul. 2018.

DAVID, René. O Direito Inglês. Tradução de Eduardo Brandão. 2. ed. São Paulo: Martins Fontes. 2006.

DWORKIN, Ronald. O Império do Direito. Tradução de Jeferson Luiz Camargo. 3. ed. São Paulo: Martins Fontes, 2014.

GOODHART, Arthur L. Determining the ratio decidendi of a case. The Yale Law Journal, v. 40, n. 2, Dec. 1930, p. 161-183.

MACCORMICK, Neil. Retórica e o Estado de Direito - Uma teoria da argumentação jurídica. Tradução de Conrado Hübner Mendes e Marcos Paulo Veríssimo. Rio de Janeiro: Elsevier, 2008.

MAUÉS, Antonio Moreira. Jogando com os precedentes: regras, analogias, princípios.

Revista Direito GV, v. 8, n. 2, São Paulo jul./dez. 2012. On-line version ISSN 2317-6172. Disponível em: <http://www.scielo.br/scielo.php?script=sci_arttext\&pid=S1808$24322012000200009 \& \operatorname{lng}=$ pt\&tlng=pt>. Acesso em: 27 jul. 2018.

RAWLS, John. Uma Teoria da Justiça. Tradução. Jussara Simões. 3. ed. São Paulo: Martins Fontes, 2008.

REIS, Elcio Fonseca. O Princípio da Boa-fé e o Planejamento Tributário. São Paulo: Quartier Latin, 2008.

SÃO PAULO. Lei n. 6.374, de 01 de março de 1989. Dispõe sobre a instituição do ICMS. Diário Oficial [do] Estado de São Paulo, São Paulo, 02 mar. 1989. Disponível em: 
<http://www.al.sp.gov.br/repositorio/legislacao/lei/1989/lei-6374-01.03.1989.html>. Acesso em: 30 jul. 2018.

Tribunal de Justiça de São Paulo. Consultas de Jurisprudência. Disponível em: <http://esaj.tjsp.jus.br/cjpg/>. Acesso em: 31 jul. 2018.

SCHAUER, Frederick. Thinking Like a Lawyer. A new introduction to legal reasoning. Cambridge: Harvard University Press, 2009. 